\title{
Improvement of Surface Characteristics for Long Life of Metal Mold by EDM in Chromium Powder Mixed Working Fluid
}

\author{
Ruixiang WANG*, Ryoji KITADA**, Ryota TOSHIMITSU*, and Akira OKADA*
}

(Received on January 24, 2017)

* Okayama University, 3-1-1, Tsushimanaka, Kita-ku, Okayama, 700-8530, Japan

** Sojo University, 4-22-1, Ikeda, Nishi-ku, Kumamoto, 860-0082, Japan

\begin{abstract}
This paper aims to form a chromium carbide containing layer on metal mold steel by EDM finishing in chromium powder mixed working fluid in order to improve the surface characteristics for long life of metal mold, such as surface hardness, corrosion resistance and releasability of molded resin. The surface characteristics of carbon tool steel with low chromium content finished by EDM in chromium powder mixed working fluid were compared to those of alloy tool steel SKD11 with high chromium content. Experimental results shows that surface hardness, corrosion resistance and releasability of molded resin could be significantly improved to the same high level for both kinds of steel by EDM finishing in chromium powder mixed fluid.
\end{abstract}

Keywords: EDM, Chromium powder mixed working fluid, Molded resin releasability, Corrosion resistance

\section{INTRODUCTION}

A high-speed milling has been often applied to shaping of the metal molds in these years. Nonetheless, electrical discharge machining (EDM) has been still applied for highly precise metal molds, since machining of hard-to-difficult materials and fine complicated shapes is easily possible. After the shaping, the surface finishing is generally done by hand operation to obtain lower surface roughness without recast layer including micro cracks. Furthermore, the surface coating is often done to improve surface hardness, wear resistance and corrosion resistance.

On the other hand, recent EDM finishing technology shows a remarkable progress, in which lower surface roughness like a mirror can be obtained by optimizing discharge conditions or by mixing metal powders into the working fluid [1-6]. Then, it is highly expected that EDM finishing will be applied as a final finishing method. In fact, the EDM finished surface has been partially used to the metal molds for semiconductor packaging with epoxy resin. In that case, the lifetime of metal molds would depend mainly on the surface characteristics of EDM finished surface. In EDM process in oil working fluid, heat resolved carbon from the fluid diffuses onto the surface, which increases the surface hardness and wear resistance. It was also reported that the surface characteristics, such as wear resistance and corrosion resistance could be improved by using powder mixed working fluids, such as silicon, aluminum, nickel powders, since crack generation was prevented to some extent, and harder and smoother surface was obtained [7-10]. When the powder is heavy metal like nickel, the powder content can be included onto the surface. This phenomenon indicates high possibility of coating by EDM, simultaneously with surface finishing. Another of practically important surface characteristics for long life of metal molds for plastic injection molding is releasability of molded resin from the metal mold surface. For the purpose, the surface coating of hard chromium carbide layer has been often applied to the mold surface after hand finishing of metal mold surface.

In this study, the formation of chromium carbide containing layer on EDM finished surface was discussed by using a chromium powder mixed working fluid (CrPMF), and the surface characteristics, such as surface hardness, corrosion resistance and releasability of molded resin were evaluated. In addition, the surface characteristics of carbon tool steel SK105 with low chromium content finished by EDM in CrPMF were compared to those of alloy tool steel SKD11 with high chromium content, and discuss the practical applicability of the EDM finished surface for low-cost steels with low chromium content as a metal mold.

\section{EXPERIMENTAL PROCEDURE}

Fig. 1 shows the schematic illustration of EDM finishing equipment. EDM experiments were carried out by using a die-sinker electrical discharge machine with linear servo motor drive (Sodick AP1L). A cylindrical copper of $25 \mathrm{~mm}$ in diameter was used as 
the electrode. The workpiece material was alloy tool steel SKD11 with high chromium content used widely for metal mold material, and SK105 without chromium content. Chromium powder of $5 \mu \mathrm{m}$ in an average particle size mixed into kerosene type working fluid is shown in Fig. 2.

EDM finishing conditions are listed in Table 1. These conditions are based on the EDM maker recommended conditions for surface finishing using silicon powder or aluminium powder mixed working fluids. These powder mixed fluids have been conventionally applied as working fluid to obtain very small surface roughness. In order to discuss the effect of chromium powder concentration in working fluid on the surface content and characteristics of EDMed surface, the concentration was varied from 0 to $3.0 \mathrm{~g} / \mathrm{L}$. The discharge current and the discharge duration were varied from 0.4 to $1.6 \mathrm{~A}$ and 2 to $7 \mu \mathrm{s}$, respectively. The working fluid was stirred with a rotating screw during EDM process to prevent the powder precipitation in the fluid.

\section{SURFACE ELEMENT AND STRUCTURE}

Component analysis of the EDM finished surfaces in kerosene type working fluid and CrPMF with different powder concentrations were carried out by using an energy dispersive X-ray spectroscopic analysis (EDX). The results are shown in Fig. 3. As shown in the graph, the chromium content of EDMed surface becomes higher with increasing chromium powder mixed concentration in the fluid. Under the same condition of chromium powder mixed concentration, chromium content on the EDMed surface of SKD11 is slightly higher than that on SK105. This is because, the initial chromium content in SKD11 is about $12 \%$. Chromium content as much as SKD11 can be included into the EDM finished surface of low chromium content material SK105 by using CrPMF.

Next, X-ray diffraction spectrum (XRD: Rigaku Smart Lab) of the surface was measured to clarify the crystal structure of surface layer. In order to identify the crystal structure of the EDMed surface using CrPMF, the EDMed surface containing much chromium was analyzed here. Fig. 4 shows the XRD spectrum on the EDM finished surface of SKD11. As shown in the figure, $(\mathrm{Cr}, \mathrm{Fe})_{7} \mathrm{C}_{3}$ and $\mathrm{Fe}_{3} \mathrm{C}$ are clearly detected but pure chromium cannot. Therefore, it was clarified that the chromium iron carbide layer could be formed on the EDM finished surface by using CrPMF. Almost similar spectrum for the EDMed surface of SK105 was also obtained.

To observe the microstructure of recast layer of EDMed SKD11using CrPMF, TEM (Transmission

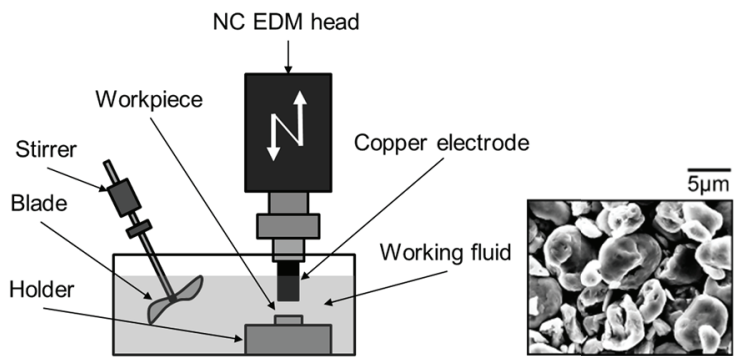

Fig. 1 Schematic illustration of Fig. 2 SEM image of EDM using CrPMF chromium powder

Table 1 EDM conditions for finishing

\begin{tabular}{|c|c|}
\hline Cr powder concentration, $C_{\mathrm{P}}$ & $0,1,3(\mathrm{~g} / \mathrm{L})$ \\
\hline Discharge current, $i_{\mathrm{e}}$ & $0.4,1.2,1.6(\mathrm{~A})$ \\
\hline Discharge duration, $t_{\mathrm{e}}$ & $2,7(\mu \mathrm{s})$ \\
\hline Electrode polarity & Negative \\
\hline Oscillation radius of electrode, $R_{\mathrm{o}}$ & $250(\mu \mathrm{m})$ \\
\hline
\end{tabular}

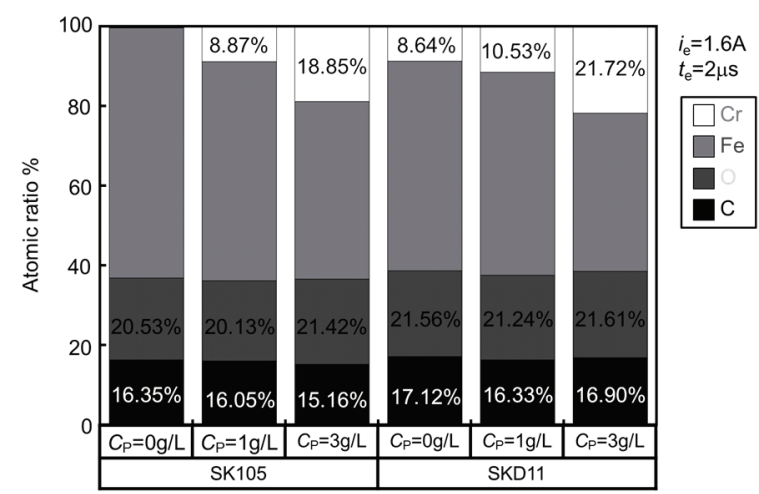

Fig. 3 Surface components of EDM finished surfaces in kerosene type working fluid and CrPMF

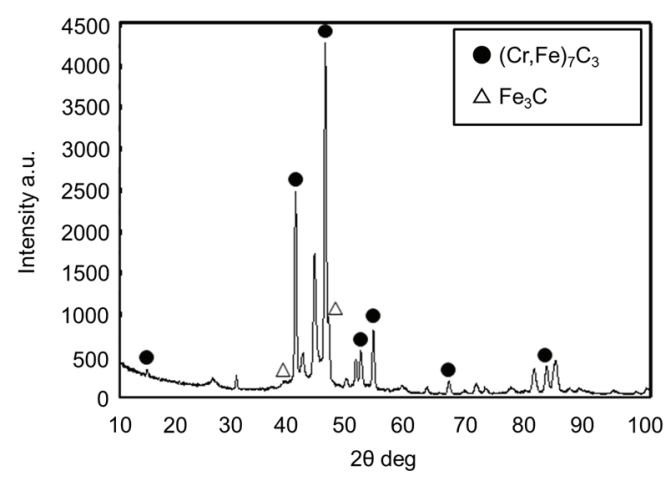

Fig. 4 X-ray diffraction spectrum of EDM finished surface in $\mathrm{CrPMF}$

Electron Microscope) observation was done. The result is shown in Fig. 5. Thin resolidified surface layer of about $3 \mu \mathrm{m}$ in thickness can be clearly observed, and it mainly consists of two layers. Near the surface, an amorphous-like layer is formed, in which crystal grain cannot be observed. Underneath 
the layer, another resolidified layer with columnar crystals is formed.

In order to investigate the chromium distribution in depth direction and the chromium containing layer thickness, line component analysis was carried out by using an EDX line analysis function equipped in SEM (Scanning Electron Microscope). The results are shown in Fig. 6. Apart from iron which is main component of SK105 and SKD11, much chromium exists near the surface layer. Therefore, it is confirmed again that the surface layer formed by EDM using CrPMF includes chromium. Also, the chromium contents on EDMed surface of SK105 and SKD11 in CrPMF are almost the same. Moreover, the chromium content decreases with the depth from the surface, and becomes almost the same as that in the matrix around the interface between the resolidified surface layer and the base matrix. Therefore, strong adhesion of the surface layer is highly expected.

\section{SURFACE CHARACTERISTICS}

\subsection{Surface hardness}

Fig. 7 shows surface hardness of EDMed surfaces of SK105 and SKD11 under different powder mixed concentrations. The hardness was done by a micro Vickers hardness tester (Matsuzawa MMT-X7). Indenter is a pyramid-shaped diamond and the indentation load was $98 \mathrm{mN}$. The hardness was measured at different 8 points for each surface, and the average values are shown in the graph. The ground surface before EDM was also tested for comparison. As shown in the figure, the surface hardness of the materials becomes higher after EDMed, and the hardness of EDMed surface increases with increasing the powder mixed concentration for both workpiece materials. Furthermore, the same trend can be seen for both SK105 and SKD11, and the hardness values are nearly the same. This is because the heat resolved carbon from kerosene type working fluid and chromium were thermally decomposed and chromium carbide formed a hard film on the EDMed surface, which agrees well with the surface component and structure shown above.

\subsection{Releasability of molded resin}

One of the important surface characteristics for long life of metal molds is releasability of molded resin from the metal mold surface. To evaluate the releasability of molded resin, tensile tester as shown in Fig. 8 was used. Workpieces were fixed on the table heated to the curing temperature $448 \mathrm{~K}$ of the epoxy resin. The EDMed surface turned upward. The jig die set on the EDMed surface was also kept at the same temperature and then a thermosetting epoxy resin was

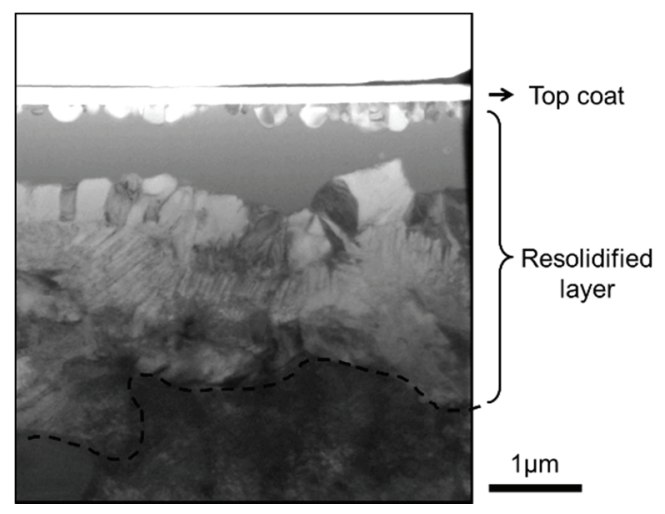

Fig. 5 TEM image of cross section of EDM finished surface in CrPMF

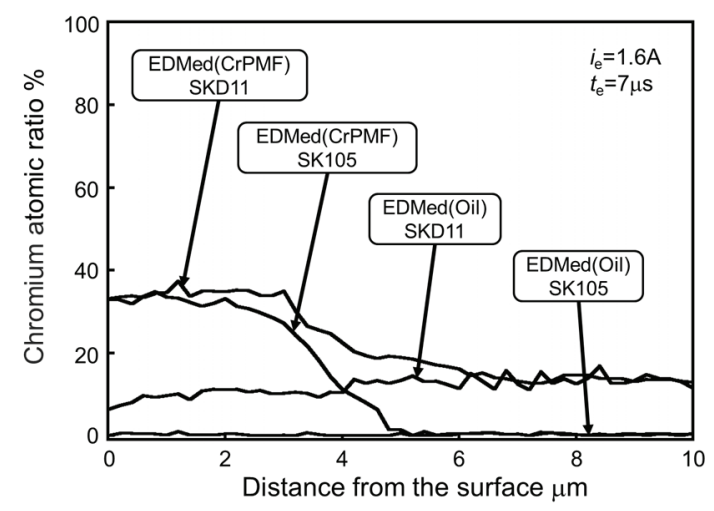

Fig. 6 Line component analysis of cross-section

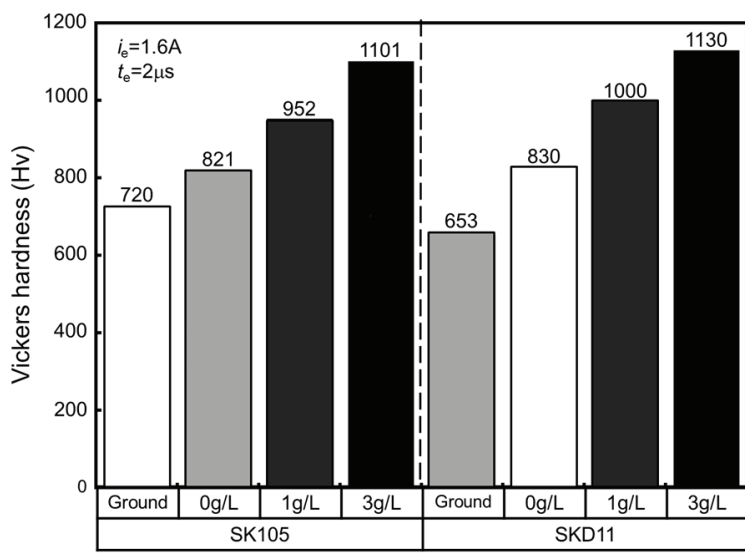

Fig. 7 Variations of Vickers hardness with machining conditions

put inside the jig. Next, the epoxy resin melted with the high temperature. During the molding, a constant compressive stress was loaded to the epoxy resin by a tungsten weight set above the epoxy resin. By the curing resin, the resin adhered to the EDMed surface. Then, the cured resin was pulled up together with the jig until the resin and the workpiece were separated.

The time variation of tensile force during the releasability test is shown in Fig. 9. It can be noticed that the tensile force increases with the time. Just 


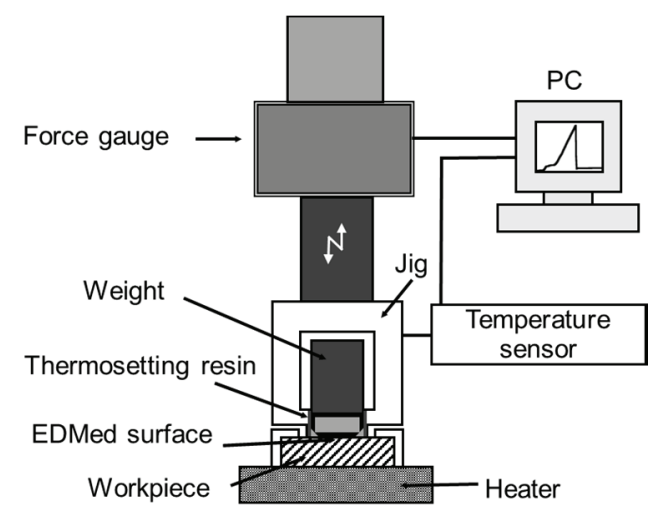

Fig. 8 Schematic illustration of releasability test

before the molding resin and the EDMed surface are separated, a maximum load appears. The maximum force is regarded as a separation force in this test, and the releasability of resin from EDM finished surface is evaluated by comparing these separation forces.

The test conditions are shown in Table 2. The thermosetting epoxy resin used in this test has been practically applied in the resin encapsulation for semiconductor packages. The releasability test conditions were determined based on the practical molding specifications of the epoxy resin.

The releasability test result are shown in Fig. 10. The separation force was measured 3 times for each sample, and the average values are shown in the graph. In any cases of the working fluid, separation forces of EDMed SK105 and SKD11 surface are almost the same. Also in the case of CrPMF, the separation force decreases by about $20 \%$, compared to kerosene type working fluid. This is because the chromium content increases on the EDMed surface by using chromium powder mixed electrical discharge machining. Chromium carbide and chromium alloy coatings have been conventionally applied to metal molds, since the releasability of molded resin can be improved [11].

From these results, molded resin releasability of EDM finished surface can be improved by using CrPMF.

\subsection{Corrosion Resistance}

Finally, corrosion resistance was evaluated. Fig. 11 shows the electrochemical analysis system to measure corrosion resistance, quantitatively. $3 \% \mathrm{NaCl}$ solution is used as an electrolyte. Ground surface or EDMed surface was set as a work electrode. For counter electrode, a platinum was used because of its low resistance and difficulty to polarize. The reference electrode was $\mathrm{Ag} / \mathrm{AgCl}$. The anodic polarization current was measured by changing the voltage between the work electrode and counter one up to $2 \mathrm{~V}$ from natural potential under the voltage sweep rate 1

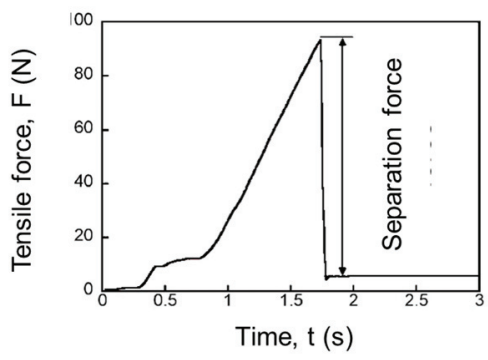

Fig. 9 Temporal change of tensile load

Table 2 Releasability test conditions

\begin{tabular}{|c|c|}
\hline Resin & Thermosetting epoxy resin \\
\hline Compression load & $1.13(\mathrm{~N})$ \\
\hline Molding temperature & $448(\mathrm{~K})$ \\
\hline Cure time & $10(\mathrm{~min})$ \\
\hline Contacting area & $154\left(\mathrm{~mm}^{2}\right)$ \\
\hline Release speed & $10(\mathrm{~mm} / \mathrm{min})$ \\
\hline
\end{tabular}

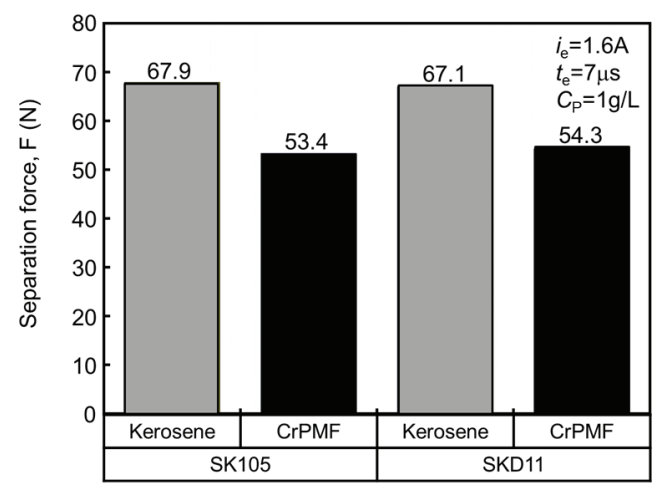

Fig. 10 Variations of separation force for various machining conditions

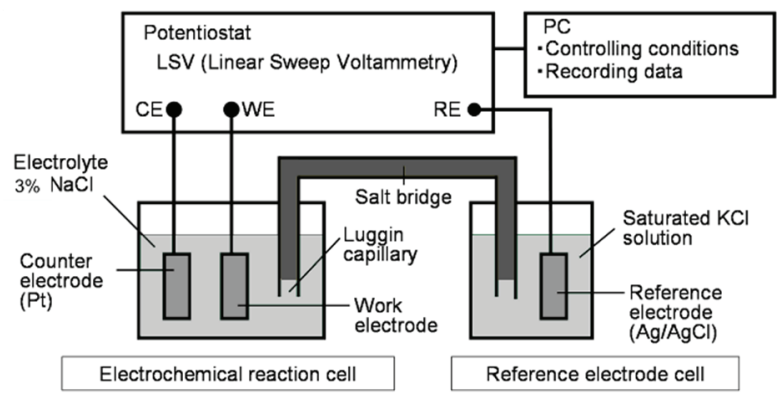

Fig. 11 Schematic illustration of electrochemical analysis system

$\mathrm{mV} / \mathrm{s}$ using a potentiostat.

Fig. 12 shows the anodic polarization current density curve of ground surface before EDM, EDMed surface with kerosene type working fluid and CrPMF of SK105. The natural potential of EDMed surface in CrPMF is higher and the electrolytic current density is much smaller than those in kerosene type working fluid, which indicates that the corrosion resistance can be greatly improved by EDM using CrPMF. It is also shown that the corrosion resistance becomes higher as 
the chromium content on EDMed surface increases. Therefore, it can be said that the content of chromium on the EDMed surface results in significant improvement of corrosion resistance.

Fig. 13 shows comparison of corrosion resistance of the EDMed surface between SK105 and SKD11 in CrPMF. It can be seen that the corrosion resistance for both materials are almost the same under the same EDM conditions.

\section{CONCLUSIONS}

In this study, a new EDM surface finishing method using a chromium powder mixed fluid was proposed, and the finished surface characteristics were examined and discussed. Main conclusions are as follows;

(1) The chromium content on EDM finished surface increases with increasing chromium powder concentration mixed into the working fluid.

(2) Chromium iron oxide layer can be formed on the EDMed surface of SKD11 and SK105 by using chromium powder mixed working fluid.

(3) By EDM finishing using chromium powder mixed working fluid, the surface hardness, molded resin releasability, and corrosion resistance of the machined surface can be increased.

\section{REFERENCES}

[1] H. Narumiya, N. Mohri N, N. Saito, H. Ootake, Y. Tsunekawa, T. Takawashi, K. Kobayashi, EDM by Powder Suspended Working Fluid. Proc. of 9th ISEM, 1989, pp. 5-8.

[2] N. Mohri, N. Saito, M. Higashi, A New Process of Finish Machining on Free Surface by EDM Methods. Annals of CIRP, 40(1), 1991, pp. 207210.

[3] Q. Y. Ming, L. Y. He, Powder Suspension Dielectric Fluid for EDM, Journal of Materials Processing Technology, 52(1), 1995, pp. 44-54.

[4] Y. Uno, A. Okada, Surface Generation Mechanism in Electrical Discharge Machining with Silicon Powder Mixed Fluid, International Journal of Electrical Machining, 2, 1997, pp. 1318.

[5] Y. S. Wong, L. C. Lim, I. Rahman, W. M. Tee, Near-mirror-finish Phenomenon in EDM Using Powder-mixed Dielectric, Journal of Materials Processing Technology, 79(1-3), 1998, pp. 30-40.

[6] T. Moro, N. Mohri, H. Otsubo, A. Goto, N. Saito, Study on the Surface Modification System with Electrical Discharge Machine in the Practical Usage, Journal of Materials Processing Technology, 149(1-3), 2004, pp. 65-70.

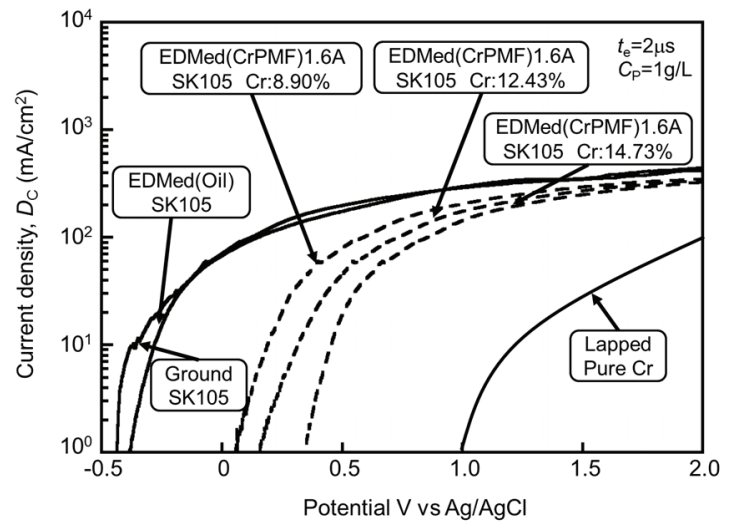

Fig. 12 Anodic polarization current curves at various machining conditions for SK105

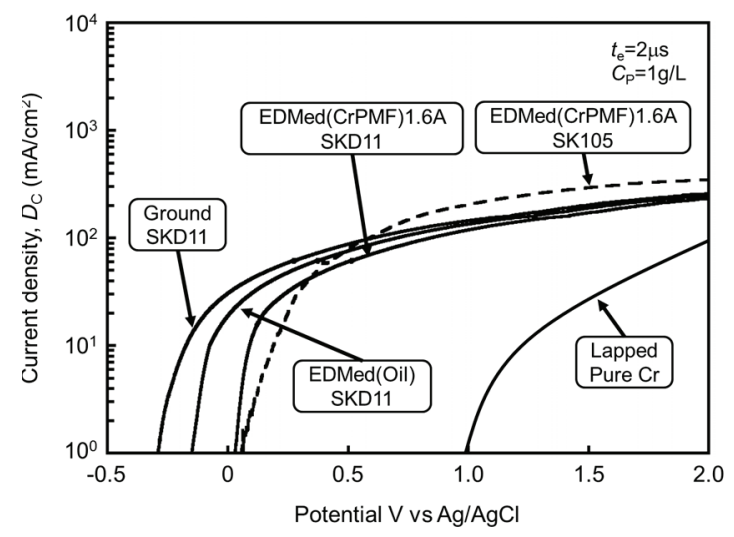

Fig. 13 Anodic polarization current curves for various workpiece materials

[7] Y. Uno, A. Okada, Y. Hayashi, Y. Tabuchi, Surface Modification by EDM with Nickel Powder Mixed Fluid, International Journal of Electrical Machining, 4, 1999, pp. 47-52.

[8] D. K. Aspinwall, R. C. Dewes, H. G. Lee, J. Simao, Electrical Discharge Alloying of Ti and Fe Workpiece Materials Using Refractory Powder Compact Electrodes and $\mathrm{Cu}$ Wire. Annals of CIRP, 52(1), 2003, pp. 151-156.

[9] K. Furutani, H. Sato, M. Suzuki, Influence of Electrical Conditions on Performance of Electrical Discharge Machining with Powder Suspended in Working Oil for Titanium Carbide Deposition Process, International Journal of Advanced Manufacturing Technology, 40(11), 2008, pp. 1093-1101.

[10] F. Q. Hu, F. Y. Cao, B. Y. Song, P. J. Hou, Y. Zhang, K. Chen, J. Q. Wei, Surface Properties of $\mathrm{SiCp} / \mathrm{Al}$ Composite by Powder-mixed EDM. Procedia CIRP 6 (1) 2013. pp. 101-106.

[11] J. Esteve, J. Romero, M. Gomez, A. Lousa, Cathodic Chromium Carbide Coating for Molding Die, Surface and Coating Tchnology, 188-189, 2004, pp. 506-510. 